\title{
Tradition and Future of the Korean Society of Plastic and Reconstructive Surgeons
}

\author{
Byung Chae Cho
}

Chairman of the Korean Society of Plastic and Reconstructive Surgeons Department of Plastic and Reconstructive Surgery, Kyungpook National University School of Medicine, Daegu, Korea

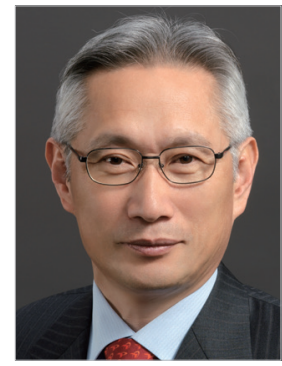

Current day Hallyu (Korean wave) culture is rapidly spreading throughout Asia and the world, moving from the periphery of global culture towards the center. 'Plastic Surgery Hallyu' has joined K-pop, TV dramas, dancing, and food as one of the pillars of the Hallyu craze, and the Korean Society of Plastic and Reconstructive Surgeons (KSPRS) is showing the world its outstanding results in both surgery and research. In 2015, The Washington Post published a portrayal of plastic surgery in Korea, saying that "South Korea is the plastic surgery capital of the world" [1].

In 2016, KSPRS will welcome the 50th anniversary of its founding. The inaugural assembly of the Korean Society of Plastic and Reconstructive Surgeons was held on May 15, 1966, initiated by around thirty professional doctors interested in the field of plastic surgery, including general surgeons, orthopedic surgeons, otorhinolaryngologists, and ophthalmologists, with Yonsei University's School of Medicine playing a key role. After this, a specialized training system was implemented in 1973, and Korea produced its first plastic surgeon specialist in 1975 [2].

Developing during the 60's and 70's into the 'Miracle on the Han River', South Korea's economy grew with dazzling speed, and this was accompanied with similarly dazzling developments in Korea's plastic surgery field. In just the short period since its founding, KSPRS has developed dynamically, growing into a large professional organization with over two thousand members. We have become the third largest such organization for plastic surgeons in the world after those in the United States and Brazil [3]. In addition, we have entered into a formal partnership with the American Society of Plastic Surgeons (ASPS), and in 2013, we participated in the ASPS's annual scientific meeting as a guest nation.

The official journal of KSPRS is the Archives of Plastic Surgery (Arch Plast Surg, APS). A Korean-language journal with the title Journal of the Korean Society of Plastic and Reconstructive Surgeons began being published in 1974, and in 2012, after the name change that accompanied its transition to being produced in English, it started being published six times yearly. A peer-reviewed journal, APS is currently indexed and tracked in the PubMed, PubMed Central, CrossRef, Scopus, Embase, and Google Scholar databases.

There have been tangible results achieved during the four years since this transition to English, and we are devoted to striving to become more than just the representative journal of Korea, but the highest quality journal for plastic surgery in the Asia-Pacific region. As part of this effort, we continue to work hard to achieve indexing in the Science Citation Index Expanded (SCIE). APS will play a central role in the development of KSPRS's clinical scholarship [4,5].

Since its founding, KSPRS has held an annual conference. The 20th anniversary of its founding in 1986 saw the invigoration of scholarly activity, which resulted in an additional spring conference held every year, and as of the 30th anniversary, an integrated scholarly conference has been held in tandem with affiliated conferences of the Korean Society for Surgery of the Hand and the Korean Society for Aesthetic Plastic Surgery.

Through these many years of dedicated work, the scholarly conference has become an international event, providing a steady foundation for advancing Korea's practice of plastic surgery onto 
the world's stage. In commemoration of the 50th anniversary of KSPRS's founding, PRS Korea 2016 is scheduled to take place November 17-20. Under the slogan '50 Years: Beginning of a New Era', we will invite many distinguished foreign scholars to the meeting and share recent advances and techniques.

Looking back at the history of KSPRS, we can understand our present position and can prepare for tomorrow's work. KSPRS will begin the work needed to plan its vision and put forward its future core values in order to become an organization that can continue in the footsteps of its 50-year tradition. Moving forward, KSPRS will expand its international footing and revitalize international exchange.

We will take steps to further expand our participation and exchange with leading international societies through meetings such as the Global Leadership Forum. We will work hard to further raise the international status of KSPRS by expanding opportunities for presenting at international conferences and by finding and fostering outstanding members. Through continued dedication, we will do everything possible to become the vanguard, taking the lead in the global era of plastic and reconstructive surgery, as we continue with our contribution to the development of the field of medicine.

\section{REFERENCES}

1. Swanson A. Wonkblog: Stunning photos show why S. Korea is the plastic surgery capital of the world [Internet]. Washington, DC: The Washington Post; c2015 [cited 2015 May 16]. Available from: http://www.washingtonpost.com/news/ wonkblog/wp/2015/05/16/stunning-photos-show-whysouth-korea-is-the-plastic-surgery-capital-of-the-world/.

2. Kim YB. The history and future of plastic and reconstructive surgery. Arch Plast Surg 2015;42:515-6.

3. Lee JH. Archives of Plastic Surgery Indexed in PubMed, PubMed Central and Scopus, and on the road to becoming an SCI(E) journal. Arch Plast Surg 2012;39:583-4.

4. Kim JT. Evolution to a renowned international journal. Arch Plast Surg 2012;39:1-2.

5. Kim YH. The current position of Archives of Plastic Surgery and its future. Arch Plast Surg 2015;42:387-90.

Correspondence: Byung Chae Cho

Department of Plastic and Reconstructive Surgery, Kyungpook National University School of Medicine, 130 Dongdeok-ro, Jung-gu, Daegu 41944, Korea

Tel: +82-53-420-5692, Fax: +82-53-425-3879, E-mail: bccho@bh.knu.ac.kr

No potential conflict of interest relevant to this article was reported.

Received: 15 Dec 2015 • Revised: 15 Dec 2015 • Accepted: 15 Dec 2015 pISSN: 2234-6163 • elSSN: 2234-6171

http://dx.doi.org/10.5999/aps.2016.43.1.1 • Arch Plast Surg 2016;43:1-2 